\title{
KRONIK
}

\section{Cumhurbaşkanının Görevi Neydi?}

Prof. Dr. Yavuz Sabuncu, A.Ü. Siyasal Bilgiler Fakültesi Öğretim Üyesi

"Memur kararnamesi krizi" tanumlamasıyla Ağustos ayında ülke gündemini uzunca bir süre işgal eden ve başbakanunun sert çkışları sonucu "devlet krizi" (?) boyutuna taşınmak istenen hukuki durumun kısa bir değerlendirmesini amaçlayan bu yazı, Cumhurbaşkanının (CB) KHK'lere ilişkin yetkisi konusuyla sinurlıdır. Dolayısıyla, KHK'ler ile hangi alanlarda düzenleme yapılamayacağı ve CB'ye sunulan adı geçen KHK'nin ilgili yetki yasasının sınırları içinde kalıp kalmadığı konusu ile yaşanan olayın çok ciddi olan siyasal boyutları yazının kapsamı dışında kalmaktadır.

Sorunun hukuki boyutunda ilk saptanması gereken şey, CB'nin KHK'ler konusundaki yetkisinin yasa yapımındaki payı ile herhangi bir benzerliğinin olmadığıdır. Gerçekten de, basit yasalar bakımından CB'nin yetkisi, bunları "yayımlamak" ya da "tekrar görüşülmek üzere" TBMM'ye geri göndermekle sinırlı olup, bu yetki yasama işlemini tamamlayıcı bir nitelik taşımamaktadır. Yasa mecliste kabul edildiğinde tamamlanmıştır ve devlet başkanının bu alandaki işlevi yalnızca yasaya bağlayıcılık ve uygulanabilirlik kazandırmaktan ibarettir. Buna karşıllk yürütmenin düzenleyici işlemlerinden olan KHK'ler, CB'nin imzası olmaksızın oluşmazlar. KHK'leri bir yasama işlemi olarak tanumlamayı denesek bile, anayasaya göre bu kararnamelerin usul ve şekil bakımından yürütme organının diğer kararnamelerinden bir farkı yoktur. CB'nin tüm öteki kararnamelerde olduğu gibi, bu KHK'ler bakımından da yaptığı şey bunları imzalayarak hukuki bir işlem haline dönüştürmektir; yani bir KHK ancak Bakanlar Kurulu ve CB'nin imzalarıla oluşur. Böyle olunca CB'ye sunulan bir metin ancak bir KHK taslağı niteliği taşıyacak, Bakanlar Kurulunun ayrı ve bağımsız bir işlemi mevcut olmadığı için bir KHK'nin geri gönderilmesi diye bir şey hukuken söz konusu olmayacaktur. Gündelik dilde ve basında, yanlış olarak, CB'nin bir KHK'yi imzalamasınn "onay", imzalamamasının ise geri gönderme ya da "veto" diye nitelendirilmesi bu hukuki durumu değiştirmez. Bu nedenle de bir KHK taslağının iki ya da daha çok kere CB'nin imzasına sunulmasi CB'nin yetkisi bakımından herhangi bir farklılik yaratmaz. Dolayısıyla, "geri gönderme" terimine takılıp, buradan sonuçlar üretmek, hele yasalarla koşutluk kurmak hiç doğru değildir.

Burada karşımıza çıkan soru, CB'nin Bakanlar Kurulunca hazırlanan KHK'leri imzalamak zorunda olup olmadığıdır. Hemen belirtmek gerekir ki, devlet başkanını herhangi bir kararnameyi imzalamaya zorlayacak hukuki bir yaptırım 
yoktur ve olması da düşünülemez. Bu konuda CB'nin davranışların belirleyecek olan onun içinde hareket etmesi beklenen anayasal konumudur. CB de, tppkı öteki anayasal organlar gibi, bu konumunun dışına çıktığ zaman -bir yaptırımı olmasa bile- görevini kötüye kullanmış olacaktır. Bu konum, anayasadaki bulanıklığa karşın, yine de parlementer sistemin tarafsız ve sorumsuz devlet başkanlığı konumu olduğuna göre, CB'nin bu role uygun davranması beklenecektir. Yani devlet başkanının, KHK'ler konusunda da, yürütmenin parlamentoya karşı siyasal bakımdan sorumlu kanadını oluşturan hükümetin kendine sunduğu her türlü kararnameyi yerindelik bakımından değerlendirmemesi, danışma ve uyarı işleviyle yetinerek imzalaması parlementer sistemin gereğine uygun davranıs olacaktır. Aksi bir tutum, CB ile parlamento çoğunluğunun desteğine sahip olan ve yürütme yetkilerini fiilen kulllanan Bakanlar Kurulu arasında parlementer sistemde tanım gereği öngörülmeyen bir çatışma yaratabilecektir.

Ne var ki, bu genel doğrudan, CB'nin açıkça hukuka/anayasaya aykırı gördüğü kararnameleri de imzalaması gerektiği sonucunu çıkarmak yanlıs olur. Tam tersine, CB'nin böyle kararnameleri imzalamaması onun anayasadan kaynaklanan görev tanımının bir gereğidir. Hemen belirtelim ki, bunu söylemek işin doğasın belirtmekten ibaret olup, ne güncel bir olaydan yola çıkarak tutum belirlemek, ne de CB'yi görev tanımının ötesine geçmeye -yetki aşımına- teşvik etmek anlamına gelir. Bir an için açıkça yetki kanununun kapsamı dışına çıkan ya da Anayasa Mahkemesinin iptal ettiği bir yasa hükmünün aynısın içeren bir KHK taslağının, CB'nin imzasına sunulduğunu düşünelim. Bu durumda da CB'nin bu taslağı imzalaması gerektiğini söylemek mümkün olabilir mi? Anayasa Mahkemesinin 1993/18 sayılı kararında "herşeyden önce Cumhurbaşkan andına ters düşer" dediği de bu değil midir? Öte yandan CB'nin yapacağ1/yaptıracağı hukuki bir değerlendirmeye dayanacak olan "görüşü" elbette hukuki tartışmaya açı olacaktır. Ne var ki, CB bir kez böyle bir sonuca vardıktan sonra, bunun "yalnızca bir görüş" olduğu gerekşesiyle CB'nin görüşüne uygun davranmasını eleştirmek anlamlı değildir. Dolayısıyla, bu kriz sürecinde, ilgili yetki kanunlarının böyle KHK'ler çıkarılmasına cevaz verip vermediği ile bu yöndeki düzenlemelerin KHK ile yapılıp yapılamayacağı tartı̧ması yerine, CB'nin görev ve yetkilerinin gündeme yerleşmiş olması bir hayli şaşırtıcıdır.

Öte yandan, CB'nun anayasaya açıkça aykırı gördü̆̈̈̈ bir taslağı -ki bu olayda KHK taslağı kendisine ilk kez sunulmadan önce ve sonra böyle gördügünü açılamıştır- önce imzalamasın sonra Anayasa Mahkemesine başvurmasını öğütlemek, yani devlet başkanından "anayasaya aykırı olduğuna inandığı bir işlemi yapmasını beklemek", sıradan kamu görevlisinden bile "anayasa hükümlerine...aykırı gördüğ̈̈" emirleri yerine getirmemesini isteyen bir anayasal düzende, hukuken olduğu kadar ahlaken de yanlıştır. Bu nedenle, 
CB'nin anayasaya aykın gördüğü bir işlemi tamamlamasını istemek düşünülebilecek bir seçenek déğildir.

Peki, CB bu gerekçeyle bu KHK'yi oluşturmayarak, acaba kendini Anayasa Mahkemesinin yerine koymuş mu olmaktadır? Bu soruya "evet" cevabı verenler, örneğin TBMM Anayasa Komisyonun ya da TBMM Genel Kurulunun bir yasa önerisini anayasaya aykırilık nedeniyle reddetmesi durumunda, onların da böyle bir "hata" yaptıkların, işi Anayasa Mahkemesine havale etmelerinin daha doğru olduğunu mu söylemek istiyorlar? Eğer böyleyse meclisin Anayasa Mahkemesinin iptal edeceğini bile bile "kıyak emeklilik" yasaların çıkarmasın eleştirmek mümkün olabilir mi? Bir başka deyişle, her çeşit yasama ve yürütme işleminde anayasa uygunluğu gözetmek yerine bu işi mahkemelerin değerlendirmesine brrakmak tüm öteki organ ve makamlan "anayasanın bağlayıcllığı ve üstünlügüünden söz eden 11.madde hükmünden bağımsız kslmak anlamina gelmez mi?

Ele alınması gereken bir başka husus da, CB'nin "açıkça hukuka aykırı olduğunu düşündüğü" kararnameleri imzalamama olanağının kabulü durumunda, bunlar hakkında Anayasa Mahkemesine başvurma yetkisinin anlamsızlaşacağ açıklanamayacağı görüşüdür. Bu sorunun cevabı zor değildir. Gerçekten de CB'nin kendisine sunulan bir KHK taslağının anayasaya uygunluğu konusunda yalnuzca kuşku duyduğu ya da kamuoyunda bu yönde ciddi iddiaların varolduğu durumlarda bu yetki -yeterince- anlamlı olacaktır. Üstelik, CB bir KHK'nin tümü değil, yalnızca bazı hükümleri bakımından anayasaya aykırılık kuşkusu taşıyor da olabilir. KHK taslağı üzerinde tek taraflı değişiklik yapması mümkün olmadığına göre, CB'nin açık hukuka aykırılık görmediği bir kararnameyi hem imzalayıp, hem de kuşku duyulan bazı hükümleri bakımından Anayasa Mahkemesine başvurması, CB'nin açıkça hukuka aykırı gördüğü kararnameleri imzalamama görevi çerçevesinde hiç de açıklanamaz değildir.

Son olarak adı geçen "KHK Krizi" vesilesiyle gündeme gelen CB'nin -parlementer sistemde bulanıklık yaratıc nitelikte olan- mevcut yetkilerinin sınırlandırılması konusuna değinmek istiyorum. Hemen belirtmek gerekir ki, CB'nin hukuka açıkça aykırı kararnameleri imzalamama görevi, 1982 Anayasasının devlet başkanun güçlendirmesiyle ilgili olmayıp, onun Cumhuriyetin ilanından bu yana yürütmenin bir kanadı -başı- olmasından kaynaklanmaktadır. Dolayısıyla CB'nin yetkileri ne ölçüde sınırlandırılırsa sınırlandirılsın, parlementer sistemin iki kanatlı yürütme modelinden vazgeçilmeksizin ve $C B$ makamı ortadan kaldırılmaksızın bu yetkinin kaldırılması da mümkün değildir. 


\section{Yugoslavya'da Miloseviç Döneminin Sonu}

Yrd. Doç. Dr. Ilhan Uzgel, A.Ü. Siyasal Bilgiler Fakültesi Öğretim Üyesi

24 Eylül 2000 'de yapılan seçimlerden muhalefetin ortak adayı Vojislav Kostunitsa'nın galip çıkması üzerine Yugoslavya'da yeni bir döneme girildi ve 13 yıldır devam eden Miloseviç yönetimi sona erdi. Böylelikle, Doğu Avrupa'da 1989 sonunda başlayan sosyalist rejimlerin yıkılması süreci yaklaşık 10 yıllık bir gecikmeyle tamamlanmış oldu.

Miloseviç 1987'de yakın arkadaşı ve onun parti içinde yükselmesine yardımcı olan Ivan Stamboliç'i saf dışı ederek Sırbistan Komünist Partisinin başına geçti ve ülkede yükselen milliyetçilik rüzgarını arkasına alarak popülerliğini giderek artırdı. Bu gelişmede iki etkenin belirleyici olduğu görülmektedir. Bunlardan birincisi, Sırplar arasında Yugoslavya içinde sürekli ezildikleri ve baskı altında oldukları yolundaki anlayış̧ı ve Miloseviç bu haksızlığı giderecek lider olarak görülüyordu. İkincisi, Kosovalı Arnavutlar, özellikle 1974 Anayasasının getirdiği geniş özerkliği kullanarak burayı fiili bir cumhuriyete dönüştürmüşlerdi ve bölgeden yoğun bir Sırp göçü vardı. İşte, Sırp tarihinde ve Ortodoksluğunda çok önemli bir yeri olan Kosova'nun elinden gitmekte olduğu düşüncesi ve Miloseviç'in bu gidişe bir son verecek lider olarak görülmesi halkın bu eski komünist yeni milliyetçi lidere olan desteğini artırmıştı. Zaten Miloseviç'in en önemli uygulamalarından biri 1989 'da Kosova'nın özerkliğini kaldırmak olacakı. Bu girişim ülkedeki gerginliği artırır ve eski Yugoslavya'nın parçalanmasına giden yolu açarken, başta aydınlar ve Kilise olmak üzere Miloseviç'in Sırp ulusal birliğini sağlayacak bir lider olarak değerlendirilmesine yol açacaktı.

Ne var ki, Haziran 1991'de Slovenya ve Hurvatistan'ın bağımsızlıkların kazanmaları, Almanya'nın ısrarı ve girişimiyle $A B$ tarafından tanınmalan ve Yugoslav ordusunun arka arkaya bu bağımsızlık ilanların önlemek için müdahalede bulunması, 1995 sonuna dek sürecek bir parçalanma sürecini başlattı ve bu durum Miloseviç'in izlediği politikada bir değişikliği gerekli kıldı. 1989-91 döneminde Miloseviç'in, eskisinden farklı olarak Sırpların denetiminde bir Yugoslavya oluşturma projesi ordunun Slovenya ve Hırvatistan'da başarılı olamaması üzerine suya düşmüştü. 1991'den, yani parçalanmanin kesinleşmesinin ardından ise Miloseviç bu kez eski Yugoslavya'da Surpların ağırlıklı olarak yaşadıkları yerleri denetim altına alma ve Bosna'yı bölme planın yürürlüğe koydu. Fakat bu plan da 1995'te önce Hurvatistan'in Krajina bölgesindeki Sırpların sürülmesi, ardından aynı yllın sonunda Dayton Anlaşmasının imzalanmasıyla başanısızlı̆̆a uğradı.

Her ne kadar Miloseviç bu başarısızlığı başarı olarak sunabildi ve hem kendi halkına hem de dünyaya Balkanlara barış getiren lider olarak popülaritesini 
arturdıysa da, Yugoslavya'nun içindeki sıkıntılar büyük ölçüde devam etti. Öncelikle, yaptırımların bazıları kaldırıldı ama bir baskı aracı olarak dıs duvar denilen ve Yugoslavya'nın ekonomik yapısın olumsuz etkileyen önlemlerin uygulanmasına devam edildi. En önemlisi Kosova sorununa bir çözüm bulunamamıştı ve İbrahim Rugova öncülüğündeki pasif direnişe bazı Arnavutlar tepki göstererek Kosova Kurtuluş Ordusunun eylemlerini artırmışlardı. Şubat $1998^{\prime}$ den itibaren tırmanan çatışmalar nedeniyle, Yugoslav güvenlik kuvvetlerinin sert önlemler alması ve yüzbinlerce Arnavut'un dağlık bölgelere kaçmak zorunda kalması üzerine Balkanlarda istikrar tekrar bozuldu ve Kosova uluslararası bir soruna dönüştü. Şubat $1999^{\prime}$ da yapılan Rambouillet (Fransa) toplantisinda Yugoslavya kendisine dayatılan, Kosova'ya NATO askerlerinin yerleştirilmesi gibi hükümleri kabul ctmeyince 24 Mart'tan itibaren ABD öncülüğündeki NATO uçakları ülkeyi bombardımana başladı. Böylece, Yugoslavya, NATO'ya savaş ilan eden ilk ve tek ülke oldu. Hem ABD'li yetkililer, hem de geleneksel olarak Sırplan kollayan Fransa ve Ingiltere artık Miloseviç yönetiminden kurtulmaya karar vermişlerdi ve Yugoslavya bu dönemde iyice Batı dünyasına yabancılaşmaya başlarken, Sırplar arasında yaygin olan haksızlığa uğramışlık inancı daha da güçlendi. Öyle ki, Miloseviç karşıtı olanlarda özellikle ABD ve NATO karşıtllğı güçlenmiş, yönetim ise hemen her türlü muhalefeti NATO ajanlığı olarak tanumlamaya başlamıştı.

Bombardıman Yugoslavya'nın boyun eğmesi üzerine Haziran 1999'da sona erdi. Dünyada belki de ilk kez bir ülke içteki bir azınlığına baskı uğradığı gerekçesiyle bombalanurken, yine ilk kez hava operasyonlarıyla bir savaş kazanılıyordu. Fakat bütün bunların sonucunda Yugoslavya için asıl önemli olan Belgrad'in Kosova üzerindeki denetimini kaybetmesi ve buranin BM tarafından yönetilmeye başlanmasıydı. Böylece, Miloseviç'in 1991'de bütün Sırpların yaşadı̆̆ı toprakları biraraya getirme ("Büyük Sırbistan") projesi gerçekleşmek bir yana, Yugoslavya 1912'den beri elinde tuttuğu (Birinci ve İkinci Dünya Savaşları hariç) Kosova üzerindeki denetimini kaybetmişti. Üstelik, Karadağ'da 1997'de Cukonoviç'in başa geçmesiyle birlikte ayrilıçı eğilimler görülmeye başlanmuş, yeni yönetim Belgrad'dan gelen talimatları dinlemeyeceğini açıklamıştı. Bu durumda Sırplar kendilerine birçok açıdan çok yakın buldukları Karadağ'ın da federasyondan ayrılması olasılığıyla karşı karşı kaldılar.

Işte 24 Eylül 2000'deki seçimler bu siyasal gelişmelerin ardından gerçekleşti. Miloseviç bu seçimlerde de daha önce uyguladığı taktiklerin benzerlerini uygulamaya sokmuş, basını ve muhalefeti baskı altına almaya çalışmış, Belgrad'da NATO ülkeleri liderlerinin yargllandığı düzmece mahkeme ve duruşmalar düzenlemişti. Fakat bir noktayı iyi göremediği anlaşılmaktadır ki, o da Batılı ülkelerin bu kez onu devirmek için hem birlikte hem de çok kararlı bir şekilde hareket etmeleriydi. Hem $A B D$, hem de Almanya ve diğer bazı $A B$ ülkeleri ülkedeki muhalefet partilerine, basına ve muhalefetin başında 
bulunduğu belediyelere miktarı 70 milyon doları bulan büyük yardımlarda bulundular. Böylelikle, Miloseviç krşısında seslerini duyurmakta zorluk çeken muhalefet partileri ve Belgrad dışına ulaşamayan muhalif basın daha etkili olmaya başladı. Özellikle ABD'nin Ulusal Demokrasi Vakfı bölge ülkelerine yönelik olarak sürdürdüğü faaliyetlerini, Yugoslavya özelinde daha da artırmıştı.

Bu arada Batılı ülkelerin çabaları yalnuzca kaynak sağlamakla da sınırlı kalmayıp "Sırp milliyetçisi" olarak takdim edilen Vojislav Kostunitsa'nun da Miloseviç'e karşı ortak aday olarak belirlenmesinde önemli rol oynadı. Böylece, geçmişte birçok defa ortak platform oluşturmaya çalışı başarılı olamayan muhalefet Batılı ülkelerin dışarıdan zorlaması ve bütün partilerin kabul edebileceği bir ismi öne çkarmasıyla Miloseviç'e karşı birleşcbildi.

Seçimler gerçekleştiğinde ve ilk sonuçlar alındığında muhalefet zaferini ilan eder ve Kostunitsa'nun oyların \% 50'sinden fazlasını aldığın savunurken Miloseviç'in denetimindeki seçim komisyonu her iki adayın da \% 50'nin altında kaldığın ileri sürerek seçimlerin iki hafta sonra yenilenmesi gerektiğini savundu. Miloseviç böylece zaman kazanmaya çalışıyordu. Fakat muhalefet partilerinin çağrısı üzerine Belgrad sokaklarında ve özellikle parlamento binasının önünde toplanan halk, artık bu kentte iyice alışılmış olan yeni bir gösteri dalgasını başlattı. Ayrıca, seçim sonuçlan tanınmazsa genel greve gidileceği açiklandı. Bu arada Yugoslav Ordusu seçim sonuçlarını tanyacağını ve herhangi bir müdahalede bulunmayacağını açıklayarak en azından kaybetmesi durumunda Miloseviç'in yanında yer almayacağını belli etmiş oldu.

Ülkedeki gerilim artarken, ilginç bir gelişme yaşandı. Belgrad'ın güneyindeki Cacak kasabasının belediye başkanının öncülüğ̈ünde bazı iş makinalarıyla harekete geçen bir grup, parlamento binasının önüne gelerek, orada bekleyen ama herhangi bir eylemde bulunmayan başkentli göstericilere katıldı ve onları da peşlerine takarak parlamentoyu bastı. Cacıklılar Belgrad'a doğru yol alırken ordu müdahale etmemiş, hatta parlamento gibi önemli bir kurum basilurken polis ciddi bir direniş göstermemişti. Ardından, yönetimin denetimindeki Sırp televizyon binası da ele geçirildi ve Miloseviçin yakın adamı olan yöneticisi göstericiler tarafından saldırıya uğradı. Baskın sonucunda Kostunitsa başkanlığın ilan etti. Bu arada kendisinden haber alınamayan ve ülkeyi terk ettiği düşünülen Miloseviç'in kendisine bağlı iyi donanımlı özel birliklerle karşı saldırıya geçip yönetimi ele alacağından da endişe edildi. Fakat kısa bir süre sonra televizyonda görülen Miloseviç "artık torunların sevmek istediğini" açıklarken, mafya bağlantısı olduğu söylenen oğlunun ise yurt dışına kaçtığı ögrenildi. Miloseviç iktidardan düşmekle birlikte bu mücadeleyi bırakmayacak, tekrar milletvekili seçilen eşi Mirjana Markoviç ve denetiminde olan Surbistan Sosyalist Partisi aracılı̆̆ıla Sırbistan siyasetini etkilemeye ve geri dönmeye çalışacaktır. 
Bu gelişme Romanya benzeri bir halk ayaklanması olarak tanımlandıysa da arada ciddi farkların bulunduğu, hatta bir uzlaşma ya da "danışılı döğüş"ün söz konusu olduğu anlaşılmaktadır. Zaten Batı basınunda ve bazı araştırma kuruluşlarının yayınlarında bir süredir Miloseviç'e görevi burakması karşılığında Kosova'daki olaylar nedeniyle Lahey Savaş Suçları Mahkemesinde yargılanmama ve kişisel servetini koruma güvencesi verilebileceği yolunda haberler yer almıştı. Kostunitsa da özellikle Miloseviç'in Lahey'deki mahkemeye teslimi konusunda çok katı bir tutum almı̧ ve bunun söz konusu olmayacağını belirtmişti. Zaten yeni devlet başkan, Miloseviç döneminin başta güvenlik güçlerinin başındakiler olmak üzere kilit kadroların değiştirme konusunda aceleci olmayacağını da açıkladı.

Iktidar değişikliğinden sonra Batılı ülkeler, aradaki 10 yıllık açığı kapamak istercesine, Yugoslavya'yı büyük bir hızla uluslararası sisteme entegre etmeye başladılar. Önce yaptırımlar kaldırıldı, Kostunitsa $A B$ doruğuna davet edildi, 8 yıldır çözülemeyen Yugoslavya'nun BM'ye üyeliği sorunu hemen çözüme bağlandı, Yugoslavya AB'nin Haziran 1999'da ortaya attığı Güneydoğu Avrupa Istikrar Paktina davet edildi.

Miloseviç'in düşüşünde birçok faktör rol oynadı. Daha önce değinilen, Batılı ülkelerin doğrudan ve dolaylı müdahalelerinin yanında, Miloseviç'in geleneksel olarak kendisini destekleyen grupların desteğini kaybettiği görüldü. Sırp ulusunu hakettiği yere getireceği umudu bağlanan Miloseviç bunu gerçekleştirememiş, Sırp ulusal birliğini sağlayamamıştı. Bu çerçevede, Kilise ve milliyetçi aydınlar Miloseviç'ten özellikle 1995 'ten itibaren desteklerini çekmişler, hatta göstericilere destek olmuşlardı. Sırp Ortodoks Kilisesi Başpiskoposunun seçim sonuçların tanıması yolundaki çağrısı bunun bir göstergesiydi.

Ayrıca, ülke giderek güvensiz bir yer olmaya başlamıştı. Önce 2000 başında Arkan'ın, ardından Savunma Bakanının birbirine benzer suikastlerde öldürülmeleri, Miloseviç'in parti içinde yükselmesini sağlayan eski arkadaşı Ivan Stamboliç'in esrarengiz biçimde kaybolması halkın güvenlik sorununu ve yönetime olan tepkisini artırmıştı.

Yugoslavya'daki bu değişimi önemli kılan iki özellik vardır. Bunlardan ilki, Miloseviç'in düşüşünün temel nedeni olan Sirp ulusal projesinin gerçekleşememesidir. Buradaki sorun, Sırpların bu projenin kendisine değil, onu hayata geçirmede taktik hatalar yapan lidere tepki göstermiş olmalarıdır. Yerine gelen Kostunitsa'nun Sırp milliyetçiliğine yapılan vurguyu sürdürmesinin altında yatan neden budur. Dolayısıyla, Sırplar bu durumdan Miloseviç'i sorumlu tutarak bu tarihsel yükten bir bakıma kendilerini sıyırma yoluna da gitmişlerdir.

Ikinci olarak, uluslararası ilişkilerin Soğuk Savaş sonrası ortamda aldığı biçim 
açısından bakıldığında, Miloseviç dönemi Yugoslavya örneği Batı'nun hem ileri sürdüğü siyasal değerlere -demokrasi, insan hakları ve azınlık hakları - hem de ekonomik sisteme- özelleştirme, devletin etkinliğinin azaltılması- karşı koymaya çalışmış ve bu çabasının karşlığını çok ağır bir bedelle ödenmiştir. Bu tür bir karşı koyuşun Irak, Küba, Kuzey Kore gibi ülkelerde çok uzun bir süredir devam ettiği düşünülürse, Yugoslav deneyimi böyle bir politikanun en azından göreli bir serbest seçim sistemi altında ve özellikle Avrupa kıtasında sürdürülmesinin çok güç olduğunu göstemiştir. Bu politikalar sonucunda Yugoslavya dışlanmış, imajı zedelenmiş, ambargoya tabi tutulmuş, bombalanmış, iç politikası manipüle edilmiş ve bir "parya" devlet statüsüne indirgenmişti. Yeni dönemde ise bütün bu alanlarda bir düzelme yaşanacağı beklenirken, Yeni Dünya Düzeni Yugoslavya'yı içine almaya şimdiden başlamıştrr. 